\title{
IncRNA PCNAP1 predicts poor prognosis in breast cancer and promotes cancer metastasis via miR-340-5p-dependent upregulation of SOX4
}

\author{
YANG YU, YANING HE, YINGBO SHAO, QI CHEN and HUI LIU \\ Department of Breast Surgery, Henan Provincial People's Hospital/People's Hospital \\ of Zhengzhou University, Zhengzhou, Henan 450003, P.R. China
}

Received October 7, 2019; Accepted May 25, 2020

DOI: $10.3892 /$ or.2020.7699

\begin{abstract}
The high metastatic rate of breast cancer is the significant cause of its poor prognosis. The long noncoding RNA (lncRNA) proliferating cell nuclear antigen pseudogene 1 (PCNAP1) plays important roles in the initiation and progression of cancers; however, its regulatory function and molecular mechanism in breast cancer metastasis remains unknown. Therefore, we investigated the roles of lncRNA PCNAP1 in breast cancer metastasis by modulating the microRNA (miR)-340-5p/SOX4 axis using quantitative real-time PCR, in vivo mouse models, nucleo-cytoplasmic separation, western blot analysis, scratch assays, Transwell assays, luciferase reporter assays and MS2-RIP, in vitro and in vivo. IncRNA PCNAP1 was found to be upregulated in human breast cancer tissues, and high lncRNA PCNAP1 levels predicted poor overall survival. Function assays showed that knockdown of lncRNA PCNAP1 suppressed the migration and invasion of breast cancer cells in vitro and in vivo. Mechanistically, lncRNA PCNAP1 functioned as a competing endogenous (ce) RNA for miR-340-5p to facilitate the expression of its target gene SRY-box transcription factor 4 (SOX4), promoting migration and invasion of breast cancer cells. Overall, we found that lncRNA PCNAP1 predicted a poor prognosis in breast cancer and promoted cancer metastasis via miR-340-5p-dependent upregulation of SOX4 expression. These results suggest that lncRNA PCNAP1 has potential as an alternative therapeutic target to suppress breast cancer metastasis.
\end{abstract}

Correspondence to: Dr Hui Liu, Department of Breast Surgery, Henan Provincial People's Hospital/People's Hospital of Zhengzhou University, 7 Weiwu Road, Jinshui, Zhengzhou, Henan 450003, P.R. China

E-mail: liuhuimed@126.com

Key words: lncRNA PCNAP1, miRNA-340-5p, SOX4, breast cancer, cancer metastasis

\section{Introduction}

Breast cancer $(\mathrm{BC})$ is a common type of cancer that seriously affects women's health (1). Despite significant advances in early diagnosis, surgical treatment, and targeted therapy for $\mathrm{BC}$, the 5-year overall survival rate remains poor owing to a high metastatic rate (2). Therefore, a better understanding of the underlying molecular and biological mechanisms involved in the carcinogenesis and development of BC may lead to novel therapies to treat this challenging disease.

Long noncoding RNAs (lncRNAs) are transcripts longer than 200 nucleotides without protein-coding potential (3). Next-generation sequencing has shown that lncRNAs are widely transcribed in the genome $(4,5)$. Although they were previously considered to represent transcriptional 'noise', emerging evidence shows that lncRNAs play critical roles in various biological processes, including cellular development and determination of cell fate (6-8). Notably, abnormal expression of lncRNAs has also been observed in the development and progression of cancer, where it leads to the dysregulation of cell proliferation, apoptosis, migration, and invasion (9-11). For example, it was found that androgen receptor negatively induced lncRNA (ARNILA) promoted invasion and metastasis in triple-negative $\mathrm{BC}$ (12). Therefore, identification of key oncogenic BC-related lncRNAs and their molecular mechanisms is important to develop novel therapeutic strategies.

lncRNA proliferating cell nuclear antigen (PCNA) has multiple roles in DNA replication and repair, and maintains genomic integrity at the genetic and epigenetic levels by interacting with chaperone proteins. It comprises at least four effective pseudogenes, proliferating cell nuclear antigen pseudogene 1 (PCNAP1), PCNAP2, PCNAP3, and PCNAP4 $(13,14)$. In addition, lncRNA PCNAP can act as an endogenous RNA via microRNA (miRNA)-dependent crosstalk. The high sequence homology of the pseudogene with its ancestral gene means they can share a common miRNA, leading to the regulation of ancestral genes. However, the relationships among lncRNA PCNAP1, miRNAs, and BC require further investigation.

Here, we investigated the expression, biological function, and potential molecular mechanisms of 1ncRNA PCNAP1 in the pathogenesis of BC. We found that IncRNA PCNAP1 
was highly expressed in tumor samples, and high lncRNA PCNAP1 levels predicted poor prognosis. Function assays showed that knockdown of IncRNA PCNAP1 suppressed the migration and invasion of breast cancer cells. Regarding the mechanism, lncRNA PCNAP1 promoted the metastasis of BC by binding and downregulating miRNA-340-5p, thus promoting the upregulation of SRY-box transcription factor 4 (SOX4) in BC cells. In conclusion, our results suggest that upregulation of PCNAP1 promotes BC metastasis by modulating the miRNA-340-5P/SOX4 axis, which may represent an alternative means of inhibiting metastasis in $\mathrm{BC}$ patients.

\section{Materials and methods}

Clinical samples. Human specimens including $70 \mathrm{BC}$ tissues and paired adjacent normal tissues were collected from patients from 1 March 2013 to 31 November 2014 at the Henan Provincial People's Hospital. The mean age of the patients was 47.90 years [standard deviation (SD) 6.84] with a range of 36 to 72 years. The fresh tissue specimens were collected and immediately placed in liquid nitrogen until use. None of the patients recruited in this study had undergone preoperative chemotherapy or radiotherapy. Follow-up was conducted and ended on May 31, 2019. Death dates was verified by phone contact with the patient's relatives or by hospital records. Overall survival (OS) time were defined according to the time after treatment. The clinicopathological variables of the patients are shown in Table I. The clinical data collection and research procedures were reviewed and approved by the Medical Ethics Committee of Henan Provincial People's Hospital. In addition, BC donors participating in the study provided written informed consent for their tissue samples to be used for scientific research.

Cell lines and culture. The human $\mathrm{BC}$ cell lines MCF7 and MDA-MB-231 were provided by the Cell Bank of the Chinese Academy of Science (Shanghai, China) and were cultivated at $37^{\circ} \mathrm{C}$ in a humidified atmosphere of $5 \% \mathrm{CO}_{2}$ using DMEM (Gibco; Thermo Fisher Scientific, Inc.) supplemented with 10\% fetal calf serum (Invitrogen; Thermo Fisher Scientific, Inc.).

Cell transfection. A short interfering RNA (siRNA) negative control (NC), si-PCNAP1, miR-340-5p mimics, miR-340-5p mimics negative control (miR-Ctrl), miR-340-5p inhibitor, miR-340-5p inhibitor negative control (inhibitor NC), pcDNA3.1-SOX4 and pcDNA3.1 empty vector (vector) were obtained from RiboBio (Guangzhou, China). Using Lipofectamine 2000 (Invitrogen; Thermo Fisher Scientific, Inc.) protocols, the siRNA NC, si-PCNAP1, miR-340-5p mimics, miR-340-5p inhibitor and NC, pcDNA3.1-SOX4 and pcDNA3.1 empty vector were introduced into MDA-MB-231 and MCF7 cells. Before plasmid transfection, the MDA-MB-231 and MCF7 cells were suspended and seeded in 6-well culture plates at $37^{\circ} \mathrm{C}$. When the cell confluence rate reached $80-90 \%$, the cell culture medium was replaced by serum-free fresh medium $3 \mathrm{~h}$ before transfection.

In vivo mouse model for analysis of metastatic capability. All animal experiments were performed at the Animal Laboratory Center of Henan Provincial People's Hospital. All experimental procedures and protocols were approved by the Institutional Animal Care and Use Committee at Henan Provincial People's Hospital, in accordance with the Guide for the Care and Use of Laboratory Animals (15). Nude mice were purchased from the Animal Husbandry Center of the Shanghai Institute of Cell Biology, Academia Sinica, Shanghai, China. Twenty-one female athymic BALB/c nude mice (weight, 19-20 g; 4-5 weeks of age) were randomized into three groups of 7 nude mice per group. Nude mice were anesthetized with $1 \%$ isoflurane, and MDA-MB-231 cells transfected with siPCNAP1 or the corresponding vector control cells $\left(5 \times 10^{5}\right.$ cells $/ 100 \mu \mathrm{l}$ of complete medium) were intravenously injected into nude mice respectively via the tail vein. Nude mice were housed in the animal research facility according to institutional guidelines, with 12-h light, and food and water ad libitum. Nude mice behavior was observed every day, and body weights were monitored every 3 days. The nude mice were euthanized as soon as the following symptoms were detected: i) Severe cachexia (weight loss approaching $25 \%$ ); ii) inability to obtain food or water; general lack of moving activities; iii) pale appearance, body coat looking unhealthy and scruffy; iv) breathing problem; v) infection at the injection site. Nude mice were anesthetized with $1 \%$ isoflurane and sacrificed by decapitation on day 16 after cancer cell injection. Their lungs were then resected for metastatic nodule counting. Tissues were fixed and embedded in paraffin according to standard procedures. A sampling of sections was taken across each lung in the following manner. Two consecutive $4-\mu \mathrm{m}$ sections were taken. Subsequently, a number of consecutive $4-\mu \mathrm{m}$ sections were discarded (approximately 30 ). This process was repeated along the entire length of each lung lobe. The sections were then stained using hematoxylin and eosin (H\&E) (scale bar, $500 \mu \mathrm{m}$ ). Acctording to the images of $\mathrm{H} \& \mathrm{E}$ staining, the lung nodule numbers were quantified microscopically by three observers. According to Salmon et al (16), the adapted 'Prolate Spheroid' model was used to calculate the tumor volume. The volume of any given lung tumor nodule was determined, on the basis of measurements of the radii of two sections and known separation between the two sections. The diameter $\left(2 \times R_{1}\right)$ of the largest tumor nodule was $6.83 \mathrm{~mm}$ and the average diameter $\left(2 \times \mathrm{R}_{1}\right)$ was $2.59 \mathrm{~mm}$, which complies with the requirements of animal welfare. Then by Salmon's equation (16), the volume of each lung tumor nodule was determined.

$$
\begin{aligned}
& \text { Tumor volume }(\mathrm{V})=(4 / 3) \times \pi \times \mathrm{R}_{1} \times \mathrm{R}_{2} ; \\
& \mathrm{R}_{1} \geq \mathrm{R}_{2} ; \mathrm{R}_{1}=\left[\left(\mathrm{a}_{2}{ }^{2}-\mathrm{a}_{1}{ }^{2}+\mathrm{D}^{2}\right)^{2} /\left(4 \times \mathrm{D}^{2}\right)+\mathrm{a}_{1}^{2}\right]^{1 / 2} ; \\
& \mathrm{R}_{2}=\left[\left(\mathrm{b}_{2}{ }^{2}-\mathrm{b}_{1}{ }^{2}+\mathrm{D}^{2}\right)^{2} /\left(4 \times \mathrm{D}^{2}\right)+\mathrm{b}_{1}{ }^{2}\right]^{1 / 2} ;
\end{aligned}
$$

where $a_{1}$ is the length (longest dimension) of section 1 and $b_{1}$ is the width (shortest dimension) of section $1, a_{2}$ is the length (longest dimension) of section 1 and $b_{2}$ is the width (shortest dimension) of section 2; $\mathrm{D}$ is the distance between section 1 and section 2 .

Bioinformatics analysis. TargetScan (http://www.targetscan. org/vert_/72) (17), EV-miRNA (http://bioinfo.life.hust.edu. cn/EVmiRNA) (18) and miRTarBase (http://miRTarBase. mbc.nctu.edu.tw/) (19) were used to predict the associations between miRNAs and mRNA, and miRcode (http://www. mircode.org/index) (20) was used to predict the binding sites shared by miRNAs and lncRNAs. 
Table I. Association between the lncRNA PCNAP1 expression level and clinicopathologic features of the BC cases (N=70).

lncRNA PCNAP1 expression [n (\%)]

\begin{tabular}{|c|c|c|c|c|}
\hline \multirow[b]{2}{*}{ Variables } & \multirow[b]{2}{*}{$\mathrm{n}$} & \multicolumn{2}{|c|}{ lncRNA PCNAP1 expression [n (\%)] } & \multirow[b]{2}{*}{ P-value } \\
\hline & & Low $(\mathrm{n}=35)(\%)$ & $\operatorname{High}(\mathrm{n}=35)(\%)$ & \\
\hline \multicolumn{5}{|l|}{ Age (years) } \\
\hline$<50$ & 30 & $16(53.3)$ & $14(46.7)$ & 0.629 \\
\hline$\geq 50$ & 40 & $19(47.5)$ & $21(52.5)$ & \\
\hline \multicolumn{5}{|c|}{ Tumor size $(\mathrm{cm})$} \\
\hline$<2.5$ & 47 & $25(53.2)$ & $22(46.8)$ & 0.445 \\
\hline$\geq 2.5$ & 23 & $10(43.5)$ & $13(56.5)$ & \\
\hline \multicolumn{5}{|l|}{ ER } \\
\hline Positive & 45 & $21(46.7)$ & $24(53.3)$ & 0.454 \\
\hline Negative & 25 & $14(56)$ & $11(44)$ & \\
\hline \multicolumn{5}{|l|}{ PR } \\
\hline Positive & 47 & $22(46.8)$ & $25(53.2)$ & 0.445 \\
\hline Negative & 23 & $13(56.5)$ & $10(43.5)$ & \\
\hline \multicolumn{5}{|l|}{ HER-2 } \\
\hline Positive & 35 & $15(42.9)$ & $20(57.1)$ & 0.232 \\
\hline Negative & 35 & $20(57.1)$ & 15 (42.9) & \\
\hline \multicolumn{5}{|c|}{ Differentiation grade } \\
\hline $\mathrm{G} 1 / \mathrm{G} 2$ & 47 & $29(61.7)$ & $18(38.3)$ & 0.005 \\
\hline G3 & 23 & $6(26.1)$ & $17(73.9)$ & \\
\hline \multicolumn{5}{|l|}{ TNM stage } \\
\hline $\mathrm{I} / \mathrm{II}$ & 40 & $28(70)$ & $12(30)$ & $<0.001$ \\
\hline III & 30 & $7(23.3)$ & $23(76.7)$ & \\
\hline \multicolumn{5}{|c|}{ Lymph node metastasis } \\
\hline No & 56 & $32(57.1)$ & $24(42.9)$ & 0.017 \\
\hline Yes & 14 & $3(21.4)$ & $11(78.6)$ & \\
\hline
\end{tabular}

BC, breast cancer; lncRNA, long noncoding RNA; PCNAP1, proliferating cell nuclear antigen pseudogene 1; ER, estrogen receptor; $\mathrm{PR}$, progesterone receptor; HER-2, human epidermal growth factor receptor-2. P-value in bold print indicates statistical significant difference.

RNA extraction and quantitative real-time PCR ( $q R T-P C R)$. The miRNAs were extracted using the miRNeasy Mini kit (cat. no. 217004; Qiagen). Poly(A) was added, and $1 \mu \mathrm{g}$ of RNA containing miRNA was reverse transcribed into cDNA to detect miR-340-5p. Primers for miR-340-5p and U6 were obtained from GeneCopoeia. To detect expression of SOX4 and lncRNA PCNAP1, total RNA was extracted using TRIzol (Invitrogen; Thermo Fisher Scientific, Inc.) and further reverse transcribed into cDNA using ReverTra Ace qPCR RT-Kit (cat. no. FSK-100; Toyobo). Expression of miRNA or SOX4 was determined in a StepOnePlus system (Invitrogen; Thermo Fisher Scientific, Inc.) using SYBR Premix Ex Taq from Takara. RT-qPCR was performed under the conditions at $94^{\circ} \mathrm{C}$ for $5 \mathrm{~min}$, followed by 40 cycles at $94^{\circ} \mathrm{C}$ for $30 \mathrm{sec}, 55^{\circ} \mathrm{C}$ for $30 \mathrm{sec}$ and $72^{\circ} \mathrm{C}$ for $90 \mathrm{sec} . \mathrm{Cq}$ value of each sample was recorded and analyzed utilizing the $2^{-\Delta \Delta \mathrm{Cq}}$ method according to Livak and Schmittgen (21). U6 or GAPDH was used as an endogenous control. The RT-qPCR primers used were as follows: lncRNA PCNAP1-forward, 5'-CACTCCACTCTCTCTTC-3' and 1ncRNA PCNAP1-reverse, 5'-CAGAAAACCGCATCT ACC-3'; U6-forward, 5'-CTCGCTTCGCA-3' and U6-reverse,
5'-AACGCTTCACGAATTTGCGT-3'; SOX4-forward, 5'-GAC CTGCTCGACCTGAACC-3' and SOX4-reverse, 5'-CCGGGC TCGAAGTTAAAATCC-3'; GAPDH-forward, 5'-GGTGGT CTCCTCTGACTTCAACA-3' and GAPDH-reverse 5'-GTT GCTGTAGCCAAATTCGTTGT-3'.

Nucleo-cytoplasmic separation. For each group, MCF7 cells were cultured in a $100-\mathrm{mm}$ culture dish $\left(\sim 5 \times 10^{6}\right.$ cells $)$ with $0.5 \mathrm{ml}$ buffer A [10 mM HEPES (pH 7.9) (Hushi, China), $10 \mathrm{mM} \mathrm{KCl}$ (Hushi), $1.5 \mathrm{mM} \mathrm{MgCl}$ (Hushi), $0.34 \mathrm{M}$ sucrose (Hushi), 10\% glycerol (Hushi), 1 mM DTT (Biosharp, China), $0.1 \%$ Triton X-100 (Biosharp), and protease inhibitor mixture (Roche, USA)]. A protease inhibitor cocktail (Sigma-Aldrich; Merck KGaA), PMSF (BBI, China), phosphatase inhibitors $\mathrm{NaF}$ (Hushi), $\mathrm{Na}_{3} \mathrm{VO}_{4}$ (Hushi, China), and $\mathrm{Na}_{4} \mathrm{P}_{2} \mathrm{O}_{7}$ (Hushi) were added. Cells were then placed on ice and washed twice with 1X pre-cooled phosphate-buffered saline (PBS). Then, $0.5 \mathrm{ml}$ buffer A was added. Cells were scraped and transferred to labeled EP tubes and placed on ice for $10 \mathrm{~min}$, before being centrifuged at $1,500 \mathrm{x} \mathrm{g}$ and $4^{\circ} \mathrm{C}$ for $10 \mathrm{~min}$. The supernatants were transferred to new EP tubes and centrifuged at $6,000 \mathrm{xg}$ 
for $10 \mathrm{~min}$ at $4^{\circ} \mathrm{C}$. The resulting supernatant was the cytoplasmic component, and the precipitate obtained by low-speed centrifugation was the nuclear component. The precipitate was washed with $500 \mathrm{ml}$ buffer $\mathrm{A}$, and then centrifuged at $1,500 \mathrm{x} \mathrm{g}$ and $4^{\circ} \mathrm{C}$ for $10 \mathrm{~min}$. This was repeated 3-4 times. The appropriate amount of buffer B [3 mM EDTA (Hushi), $0.2 \mathrm{mM}$ EGTA (Hushi), $1 \mathrm{mM}$ DTT, and protease inhibitor mixture] was determined, and cocktail and $\mathrm{NaF}$ were also added ( $100 \mu 1$ per sample). The precipitate was cleaned with buffer $\mathrm{B}$, transferred to a tissue grinder, and ground 20-30 times. It was then transferred to a new EP tube, placed on ice for $30 \mathrm{~min}$, and centrifuged at $6,000 \mathrm{x}$ g for $10 \mathrm{~min}$ at $4^{\circ} \mathrm{C}$. The resulting supernatant was the nuclear component.

Western blot analysis. Cells were collected $48 \mathrm{~h}$ after transfection and lysed in $2 \mathrm{X}$ sodium dodecyl sulfate (SDS) sample buffer [100 mM Tris-HCl (pH 6.8), 10 mM EDTA, 4\% SDS, and $10 \%$ glycine] to extract total protein. The protein was quantified by bicinchoninic acid (BCA) analysis. Protein extractions were separated by $10 \%$ SDS-PAGE (20 $\mu \mathrm{g}$ per lane), and transferred onto polyvinylidene fluoride (PVDF) membranes. Membranes were blocked in 5\% milk at room temperature, incubated with primary antibody in TBST with 5\% BSA overnight at $4{ }^{\circ} \mathrm{C}$, then incubated with fluorescent-tagged secondary antibody at room temperature for $1 \mathrm{~h}$, and read using enhanced chemiluminescence (Santa Cruz Biotechnology, Dallas, USA). anti-E-cadherin (dilution 1:2,000; product code ab76055), anti-N-cadherin (dilution 1:2,000, product code ab18203) and anti-SOX4 (dilution 1:5,000; product code ab134107) were purchased from Abcam, anti-GAPDH (dilution 1:1,000; cat. no. D16H11) were purchased from Cell Signaling Technology. Secondary antibodies were mouse anti-rabbit IgG-HRP (dilution 1:10,000; cat. no. sc-2357) and bovine anti-mouse IgG-HRP (dilution 1:10,000, cat. no. sc-2371), both purchased from Santa Cruz Biotechnology.

In vitro scratch assays. A horizontal line was drawn on the back of each 6-well plate using a marker pen before the in vitro scratch assays. After digestion with $0.25 \%$ trypsin, $5 \times 10^{5}$ cells were seeded into each well to form a cell monolayer. A 20- $\mu 1$ pipette tip was used to scrape a straight line perpendicular to the horizontal line on the flat cell monolayer, and the cells were washed three times with PBS to remove floating cell debris. Then, serum-free medium was added, and the cells were cultured in a $37^{\circ} \mathrm{C}$ incubator containing $5 \% \mathrm{CO}_{2}$. Each plate was photographed at two time points ( 0 and $48 \mathrm{~h}$ ) to observe the healing of the scratches, and the cell healing index was calculated as follows: (Initial scratch width-scratch width at the time of experiment)/initial scratch width $\mathrm{x} 100 \%$. The experiment was repeated three times (Magnification, x200, scale bar, $100 \mu \mathrm{m}$ ).

Transwell assays. Transwell assays were used to assess the aggressiveness of BC cells. We used Transwell chambers (Corning) coated with Matrigel (BD Biosciences). The trypsin-treated transfected cells (containing $1 \times 10^{5}$ cells per $100 \mu \mathrm{l}$ of serum-free DMEM) were inoculated into the upper chamber. DMEM (500 $\mu \mathrm{l})$ supplemented with $20 \%$ fetal calf serum was added to the lower chamber. After incubation for $72 \mathrm{~h}$ at $37^{\circ} \mathrm{C}$ in a humidified environment containing $5 \% \mathrm{CO}_{2}$, the $\mathrm{BC}$ cells invading the lower chamber were fixed with methanol and stained with crystal violet. The invading cells were photographed using an inverted microscope (magnification, x200, scale bar, $100 \mu \mathrm{m}$ ).

Luciferase reporter assays. The wild-type (WT) or mutant human SOX4 3' untranslated region (UTR) sequences with many potential binding sites were expanded and cloned into the pGL3-Basic vector (Promega Corp.). 293T cells were transfected together with a mixture of $0.02 \mu \mathrm{g}$ of pGL3-Basic-SOX4 and $150 \mathrm{nM}$ of miRNA-340-5p mimetic. Forty-eight hours after transfection, firefly luciferase activity and Renilla reniformis luciferase activity were detected using Dual-Luciferase reporter assay system (Promega Corp.), and Renilla luciferase activity was normalized to firefly luciferase activity.

MS2-RIP. MCF7 cells were co-transfected with pSL-MS2, pSL-MS2-PCNAP1, and pSLMS2-mut (miRNA-340-5p) with pMS2-GFP (AddGene, USA). After $48 \mathrm{~h}$, cells were used to perform RNA immunoprecipitation (RIP) experiments as previously described (22). The RNA fraction isolated by RIP was analyzed by RT-qPCR.

Statistical analysis. Statistical analyses were performed using GraphPad Prism 6 software (GraphPad Software, Inc.). Data are presented as mean \pm SEM. The Student's t-test was used to analyze differences between groups. Differences among more than two groups were evaluated by one-way analysis of variance, followed by post hoc multiple comparison with the Tukey test. The Chi-square test was performed to analyze the count data. Pearson correlation analysis was performed to investigate associations. The Kaplan-Meier method was used to analyze survival rates, and the log-rank test was performed to compare the differences. A multivariate analysis of all the variables that were found to be significantly correlated in the univariate analysis was performed using a Cox proportional-hazards regression model. Two-sided P-values $<0.05$ were considered to indicate a statistically significant difference.

\section{Results}

IncRNA PCNAPI is upregulated in human BC tissues and high lncRNA PCNAPI levels predict poor overall survival. To determine the involvement of lncRNA PCNAP1 in the development of BC, we collected 70 pairs of BC tumor tissues and paired adjacent normal tissues. The correlations of lncRNA PCNAP1 expression with clinicopathological features of BC patients are shown in Table I. Based on statistical analyses of our results, high lncRNA PCNAP1 expression was significantly correlated with differentiation grade, TNM stage, and lymph node metastases in $\mathrm{BC}$ patients $(\mathrm{P}<0.05)$. However, the expression of lncRNA PCNAP1 was not associated with other clinicopathological factors of $\mathrm{BC}$ patients, including age, tumor size, estrogen receptor (ER), progesterone receptor (PR), and human epidermal growth factor receptor 2 (HER-2) status $(\mathrm{P}>0.05)$. These data indicate that upregulation of IncRNA PCNAP1 may have a critical role in BC progression. We then performed RT-qPCR to check the relative expression levels of IncRNA PCNAP1. We found that the basal expression level of IncRNA PCNAP1 in BC was 0.217, which was significantly 
A
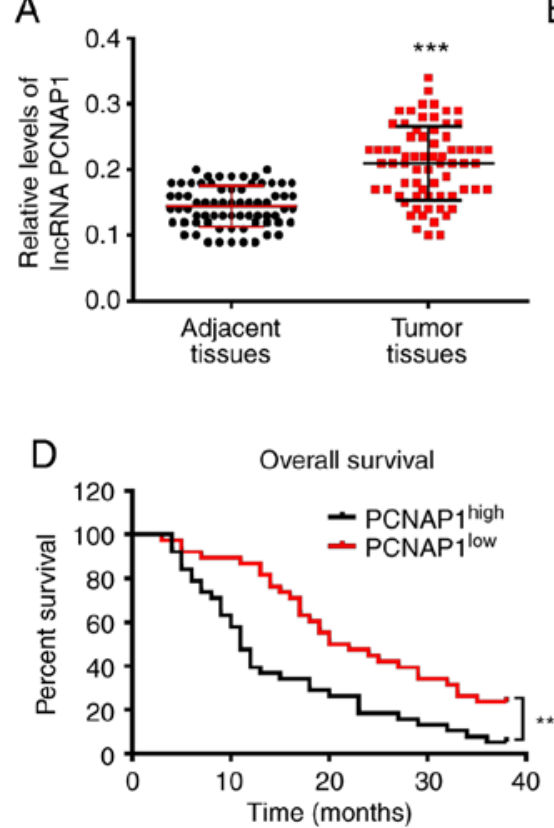

B

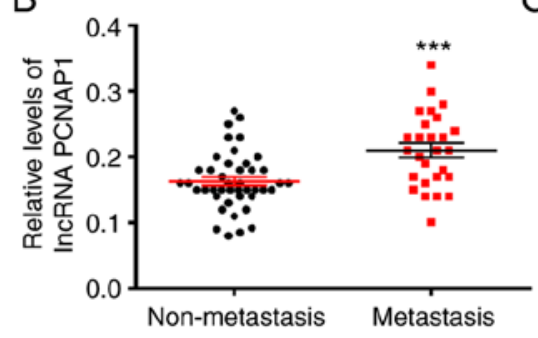

$\mathrm{E}$

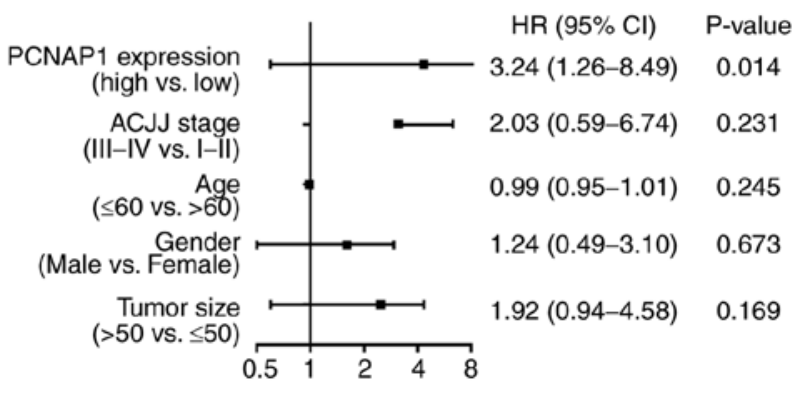

Figure 1. lncRNA PCNAP1 is upregulated in human BC tissues, and high lncRNA PCNAP1 levels predict poor overall survival. (A) RT-qPCR results showed that PCNAP1 was significantly increased in BC tissues compared with that in adjacent normal tissues. (B) Tumor samples from patients with metastasis displayed increased lncRNA PCNAP1 levels compared with those in patients without metastasis. (C) Samples were divided into low (below the median, $\mathrm{n}=35$ ) and high (above the median, $\mathrm{n}=35$ ) lncRNA PCNAP1 expression groups according to the mean level of lncRNA PCNAP1. (D and E) An increased level of lncRNA PCNAP1 was significantly associated with poor overall survival (HR 3.24; 95\% CI 1.26-8.49; P=0.014). Results are representative of three independent experiments. Data are shown as mean $\pm \mathrm{SD} .{ }^{* *} \mathrm{P}<0.01,{ }^{* * *} \mathrm{P}<0.001$. BC, breast cancer; lncRNA, long noncoding RNA; PCNAP1, proliferating cell nuclear antigen pseudogene 1 .

higher than that in corresponding adjacent healthy tissues $(\mathrm{P}<0.001)$ (Fig. 1A). Intriguingly, patients with metastasis had higher lncRNA PCNAP1 levels compared with those without metastasis $(\mathrm{P}<0.001)$ (Fig. 1B). Kaplan-Meier survival analysis and log-rank tests were performed to further assess the clinical significance of IncRNA PCNAP1 in the prognosis of BC patients. We divided the samples into low (below the median, $\mathrm{n}=35$ ) and high (above the median, $\mathrm{n}=35$ ) lncRNA PCNAP1 expression groups based on to the mean level of lncRNA PCNAP1; the cut-off value for determining low expression/high expression was 0.190 , and the mean expression level was 0.202 (Fig. 1C). An increased level of lncRNA PCNAP1 was significantly associated with poor overall survival (OS) [hazard ratio (HR), 3.24; 95\% confidence interval (CI), 1.26-8.49; $\mathrm{P}=0.014]$ (Fig. 1D and E). Taken together, these data suggest that increased lncRNA PCNAP1 expression may have an important role in the development and progression of $\mathrm{BC}$.

Knockdown of IncRNA PCNAPl suppresses the migration and invasion of breast cancer cells in vitro and in vivo. To explore the role of IncRNA PCNAP1 in BC progression, loss-of-function experiments using siRNAs (siPCNAP1\#a and siPCNAP1\#b) and CCK-8 assays were performed in breast cancer cell lines MDA-MB-231 and MCF7. Levels of lncRNA PCNAP1 expression were markedly decreased in both cell types; by $\sim 80 \%$ or $\sim 70 \%$, respectively, compared with the scrambled controls $(\mathrm{P}<0.001$ in MDA-MB-231; $\mathrm{P}<0.01$ in MCF7) (Fig. 2A and B). However, no significant effect of lncRNA PCNAP1 knockdown on BC cell viability was observed, consistent with the results of the CCK- 8 assays (Fig. 2C and D). Given that lncRNA PCNAP1 levels were increased in metastatic samples, we conducted cell migration, invasion, and wound healing assays to determine whether there was an effect on BC cell metastasis. Loss of lncRNA PCNAP1 significantly decreased the speed of scratch closure in the two BC cell lines: By $~ 64 \%$ ( $\mathrm{P}<0.01)$ in MDA-MB-231 and by $\sim 82 \%(\mathrm{P}<0.001)$ in MCF7 (Fig. 2E-H). In addition, inhibition of lncRNA PCNAP1 decreased invasion dramatically, as shown by the Transwell invasion assay results $(\mathrm{P}<0.01)$ (Fig. 2I-K). Cells with lncRNA PCNAP1 knockdown showed prominently increased protein levels of epithelial marker E-cadherin, and decreased levels of mesenchymal marker N-cadherin (Fig. 2L). Furthermore, we explored the role of lncRNA PCNAP1 in metastasis of BC in vivo by tail vein injection with highly aggressive siCtrl and siPCNAP1 MDA-MB-231 cells. As shown in Fig. 2M and N, histological examination confirmed that the injection of siCtrl cells led to lung metastasis in BALB/c nude mice; these metastases were obviously inhibited in the nude mice injected with siPCNAP1 cells. Furthermore, lncRNA PCNAP1 knockdown also obviously descreased the volume of tumor nodules in the lung (Fig. 2O). However, the weight of mice did not change after injection of siPCNAP1 cells (Fig. 2P). Taken together, these data suggest that IncRNA PCNAP1 is a positive regulator of migration, invasion, and epithelial-mesenchymal transition both in vitro and in vivo.

miR-340-5p has a target relationship with lncRNA PCNAP1 and is downregulated in $B C$. It has been demonstrated that lncRNAs usually function as miRNA sponges to regulate the binding of endogenous miRNAs to their target mRNAs (9). First, we separated MCF7 cells into nuclear and cytoplasmic 

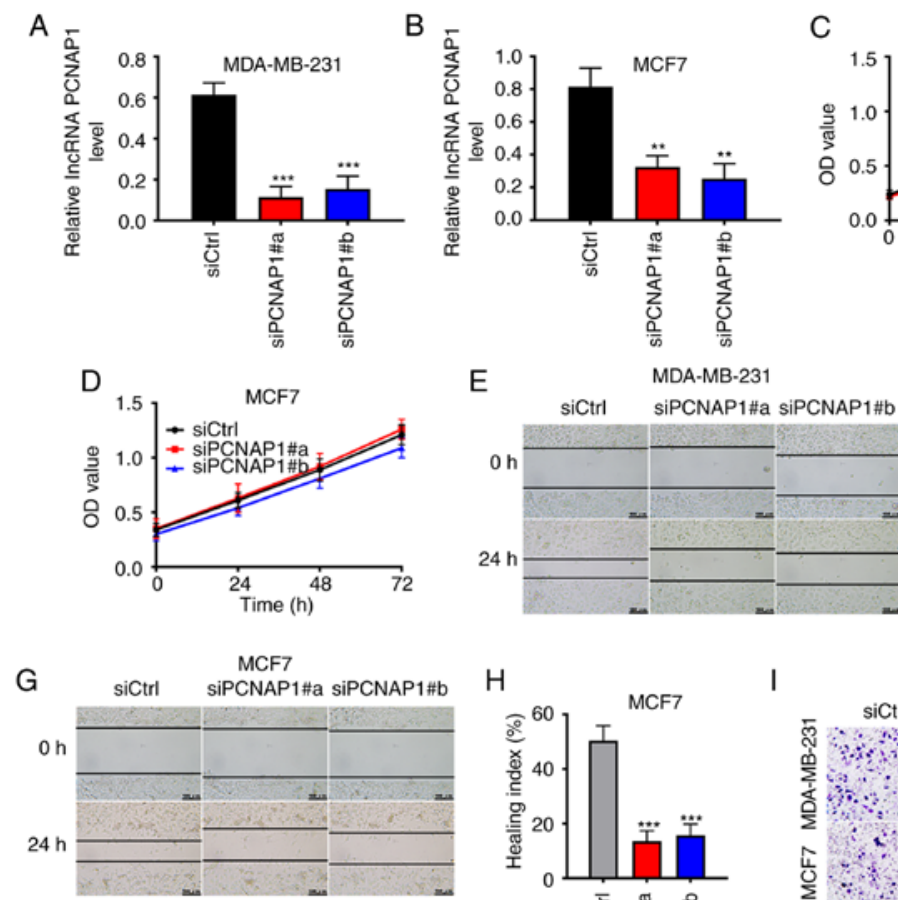

$\mathrm{H}$

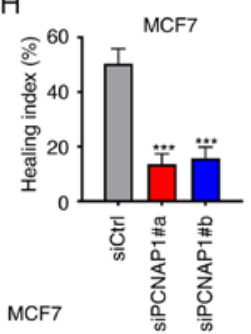

I
C

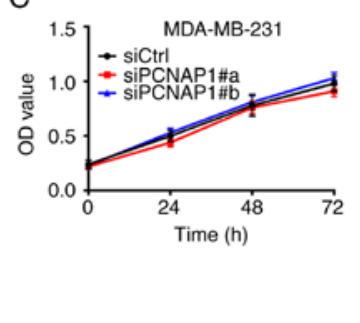

$\mathrm{F}$

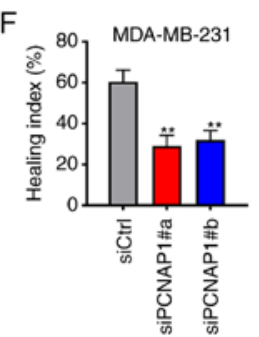

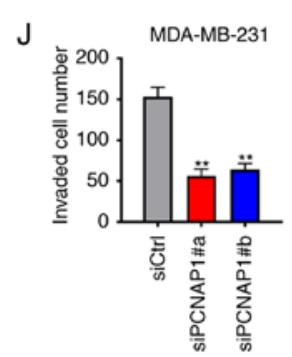
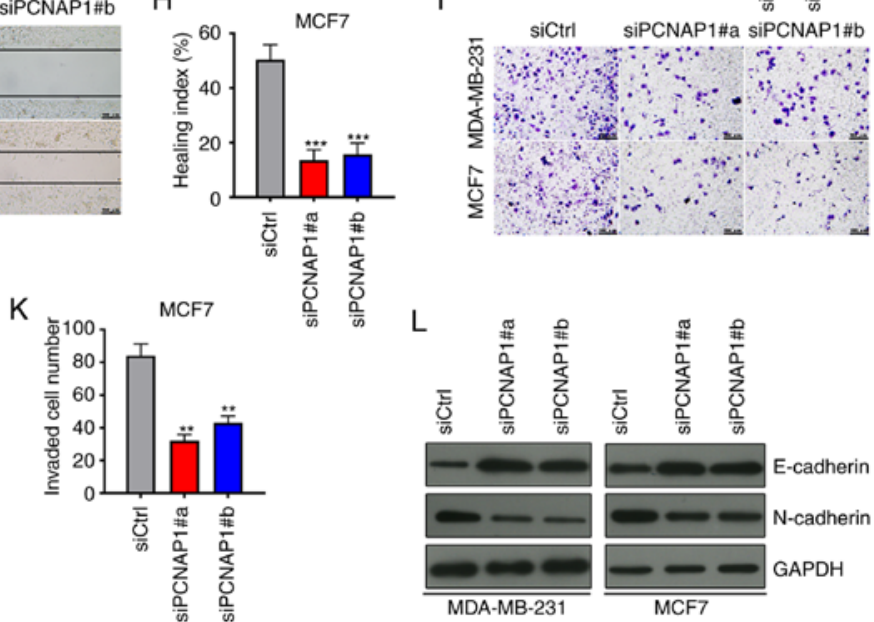

M
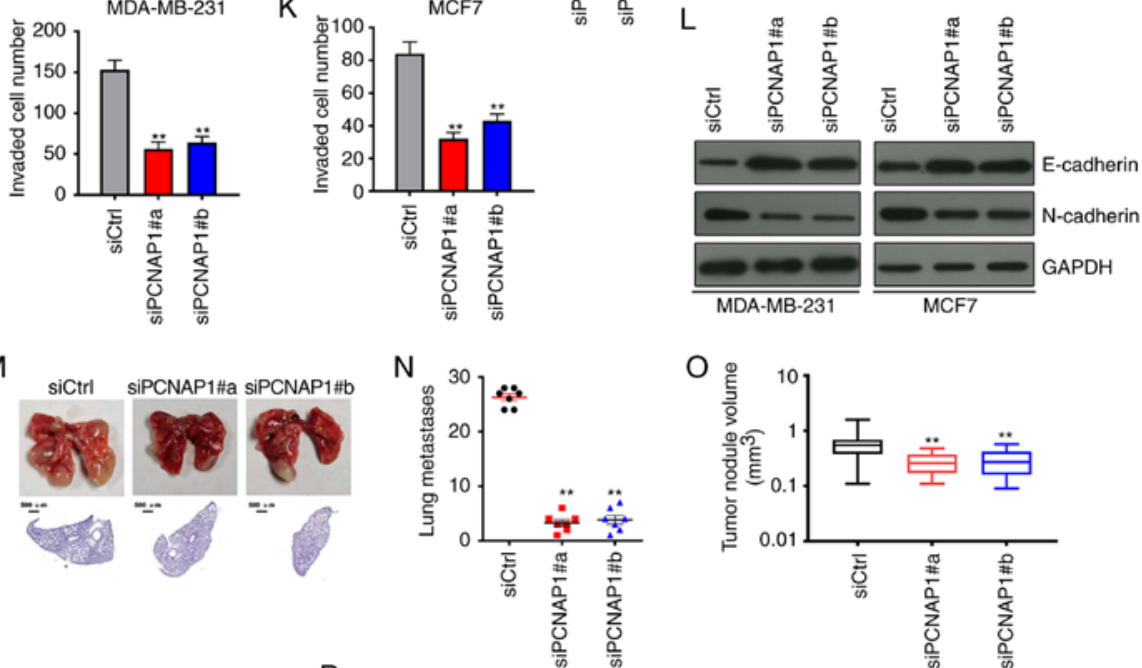

$\mathrm{P}$
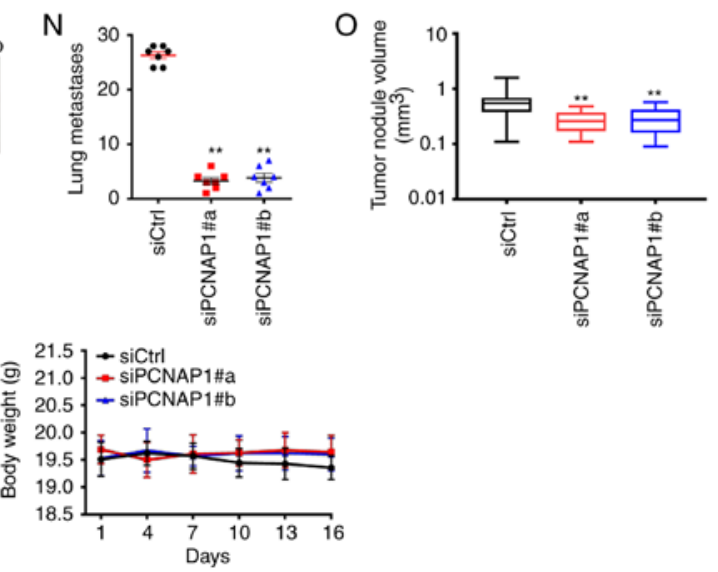

Figure 2. Knockdown of lncRNA PCNAP1 suppresses the migration and invasion of BC cells in vitro and in vivo. (A and B) Loss-of-function experiments showed that lncRNA PCNAP1 expression levels were markedly decreased following transfection with siPCNAP1\#a and siPCNAP1\#b compared with scrambled controls (siCtrl) in BC cells (by $~ 80$ and $~ 70 \%$ in MDA-MB-231 and MCF7 cells, respectively). (C and D) Knockdown of lncRNA PCNAP1 had no significant effect on BC cell viability in MDA-MB-231 and MCF7 cells, as confirmed by CCK-8 assay results. (E-H) Loss of lncRNA PCNAP1 significantly decreased the speed of wound closure in BC cells (by $\sim 64$ and $~ 82 \%$ in MDA-MB-231 and MCF7 cells, respectively). (I-K) Transwell invasion assays showed that lncRNA PCNAP1 inhibition significantly reduced invasion. (L) Cells with lncRNA PCNAP1 knockdown (siPCNAP1\#a and siPCNAP1\#b) showed observably increased protein levels of epithelial marker E-cadherin, and decreased levels of mesenchymal marker N-cadherin. (M and N) Injection of siCtrl cells led to lung metastasis in BALB/c nude mice; these metastases were inhibited in nude mice injected with siPCNAP1-transfected MDA-MB-231 cells. (O) Lung metasasis tumor volume of nude mice. Results are representative of three independent experiments. (P) Changes in nude mouse body weight. Data are shown as mean $\pm \mathrm{SD} .{ }^{*} \mathrm{P}<0.05,{ }^{* *} \mathrm{P}<0.01,{ }^{* * * *} \mathrm{P}<0.001$, compared with the siCtrl group. BC, breast cancer; IncRNA, long noncoding RNA; PCNAP1, proliferating cell nuclear antigen pseudogene 1 .

fractions and identified the cellular localization of lncRNA PCNAP1. Both U6 and GAPDH were used as control groups. As shown in Fig. 3A, 80.1\% of lncRNA PCNAP1 was detected in the cytoplasm fraction in the MCF7 cells, suggesting that it may act at the post-transcriptional level. To further explore the molecular mechanisms, we used bioinformatic tools to predict 


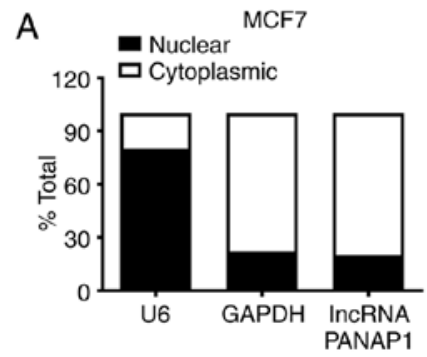

C

\begin{tabular}{|c|c|}
\hline \multicolumn{2}{|c|}{ Predicted consequential pairing of target region (top) and miRNA (bottom) } \\
\hline Position 565-572 of PCNAP1 & 5'...TAAGTTACTTAAATTTCTTTAT A ACA...3' \\
\hline & \|\|\|\| $\mid$ \\
\hline hsa-miR-340-5p & 3' UUAGUCAGAGUAACGAAAUAUU \\
\hline IncRNA PCNAP1-MUT & 5'...TAAGTTACTTAAATTTGAAAUAUUA...3' \\
\hline Position $960-966$ of PCNAP1 & 5'...AAATATTCCTTCTGATTTT TA TAACA...3' \\
\hline & \|\|\|\| \\
\hline hsa-miR-340-5p & 3' UUAGUCAGAGUAACGAAAUAUU \\
\hline IncRNA PCNAP1-MUT & 5'...AAATATTCCTTCTGATTAAAUAUUCA ...3' \\
\hline
\end{tabular}

E
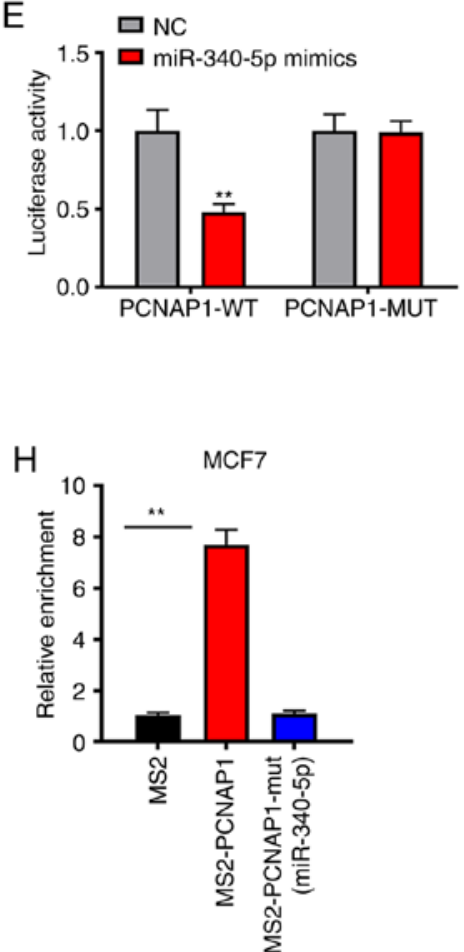

B

\begin{tabular}{|c|c|c|c|}
\hline NO. & Score & miRNA & SOX4 mRNA \\
\hline 1 & 90 & hsa-miR-340-5p & Yes \\
\hline 2 & 89 & hsa-miR-548c-3p & Yes \\
\hline 3 & 89 & hsa-miR-6890-3p & Yes \\
\hline 4 & 85 & hsa-miR-6827-5p & Yes \\
\hline 5 & 83 & hsa-miR-4671-3p & No \\
\hline
\end{tabular}
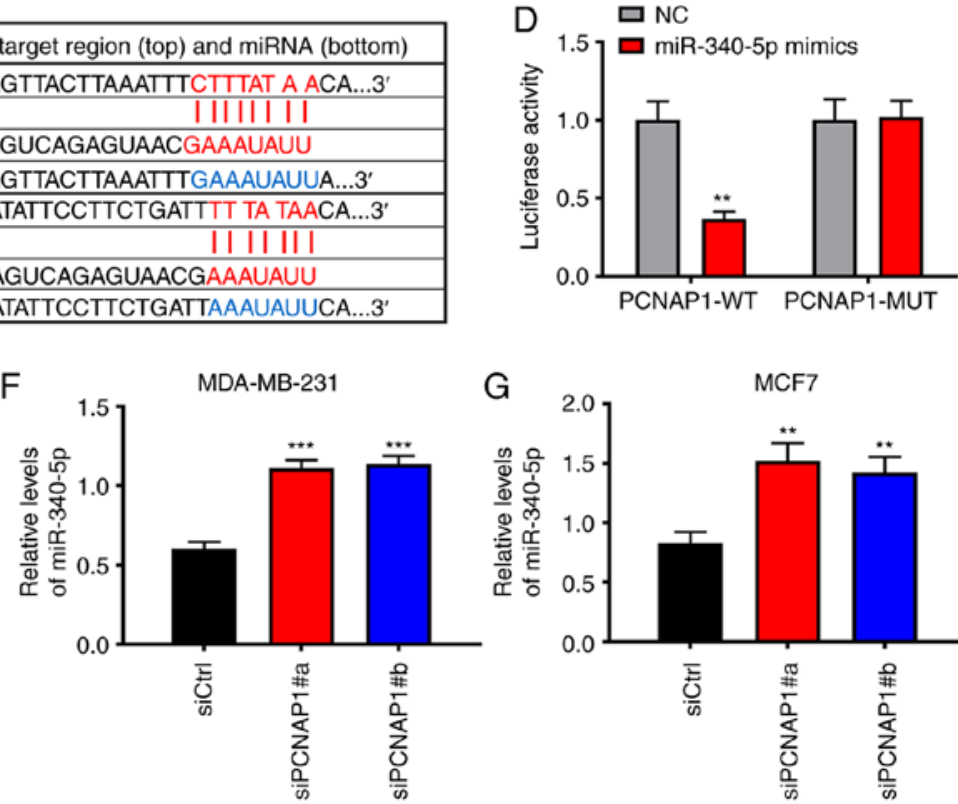

G $\quad$ MCF7

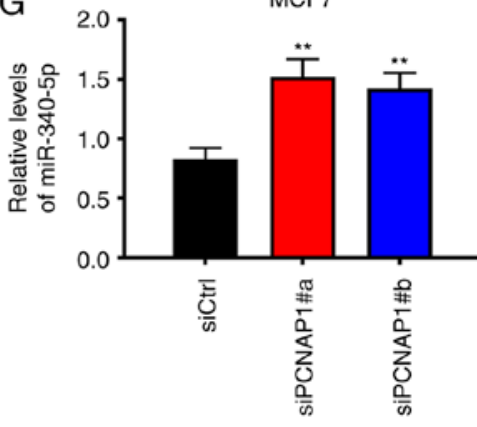

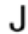

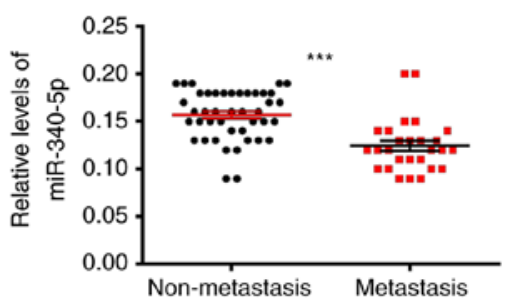

Figure 3. miR-340-5p has a target relationship with 1ncRNA PCNAP1 and is downregulated in BC. (A) 1ncRNA PCNAP1 at 80.1\% was found in the cytoplasmic fraction of MCF7 cells. (B) The first four miRNAs predicted by the TargetScan software to bind to lncRNA PCNAP1 all directly targeted SOX4. (C) Predicted binding sites of miR-340-5p and lncRNA PCNAP1 according to miRcode. (D and E) miR-340-5p mimics inhibited the luciferase activity of IncRNA PCNAP1-WT by $\sim 60 \%$ but did not affect the luciferase activity of lncRNA PCNAP1-MUT in MDA-MB-231 and MCF7 cells. ${ }^{* *}$ P $<0.01$, compared with NC. ( F and G) Knockdown of lncRNA PCNAP1 significantly increased miR-340-5p expression in both MDA-MB-231 and MCF7 cell lines. ${ }^{* *}<0.01$, ${ }^{* * * *} \mathrm{P}<0.001$, compared with the siCtrl group. (H) MS2-RIP followed by miRNA RT-qPCR was used to detect levels of miRNA-340-5p endogenously associated with lncRNA PCNAP1. ${ }^{* *} \mathrm{P}<0.01$. (I) miR-340-5p expression was significantly lower in BC tissues compared with that noted in the adjacent non-tumor tissues. ${ }^{* *} \mathrm{P}<0.01$. (J) miR-340-5p expression was significantly lower in metastatic BC tissues compared with non-metastatic tissues. ${ }^{* * *} \mathrm{P}<0.001$. Results are representative of three independent experiments. Data are shown as mean \pm SD. BC, breast cancer; lncRNA, long noncoding RNA; PCNAP1, proliferating cell nuclear antigen pseudogene 1; SOX4, SRY-box transcription factor 4; MUT, mutant; WT, wild-type.

miRNAs that could bind lncRNA PCNAP1. Surprisingly, the first four miRNAs identified using the TargetScan software were all predicted to target SOX4 directly (Fig. 3B). The association between SOX 4 and BC migration has been investigated previously $(12,23)$. Of these four miRNA candidates, we focused on miR-340-5p, which could bind lncRNA PCNAP1 according to miRcode predictions (Fig. 3C). Furthermore, we cloned wild-type (WT) lncRNA PCNAP1 luciferase plasmids containing potential miR-340-5p binding sites or mutants (MUT) for each site. Luciferase assays were performed to confirm the interaction between miR-340-5p and lncRNA PCNAP1 after transfecting the plasmids with miR-340-5p mimics into MBA-MD-231 and MCF7 cells. The miR-340-5p mimics substantially inhibited the luciferase activity of WT lncRNA PCNAP1, by $\sim 60 \%(\mathrm{P}<0.01)$; however, they did not affect the luciferase activity of the IncRNA PCNAP1-MUT 

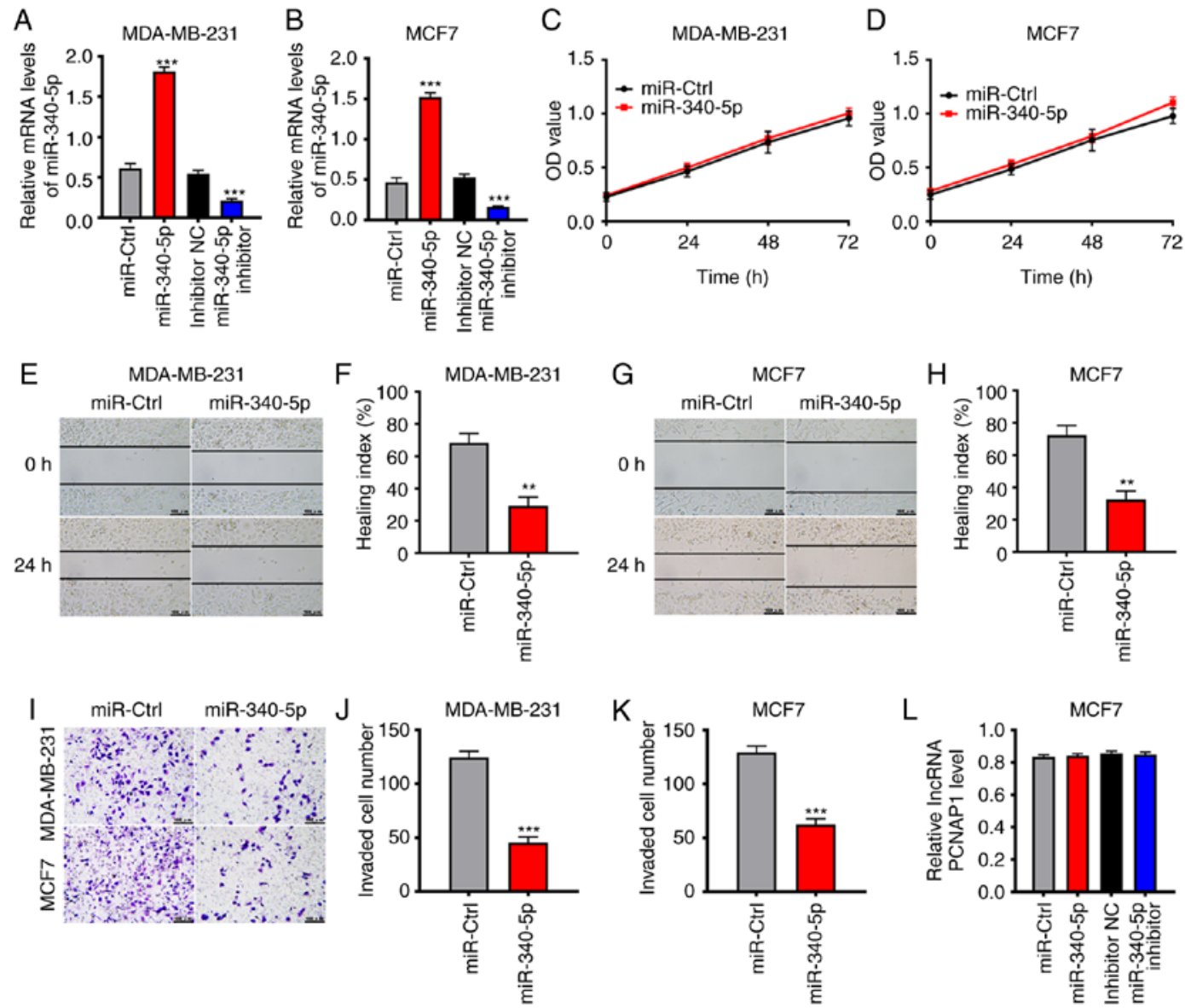

Figure 4. IncRNA promotes the migration of BC cells by downregulating miR-340-5p. (A and B) Transfection of miR-340-5p mimics significantly upregulated the expression of miR-340-5p in MDA-MB-231 and MCF7 cells compared with the miR-ctrl group ${ }^{* * *} \mathrm{P}<0.001$, compared with the miR-ctrl group. Transfection of miR-340-5p inhibitor obviously downregulated the expression of miR-340-5p compared with the inhibitor NC group, indicating successful transfection. ${ }^{* * * *} \mathrm{P}<0.001$, compared with the inhibitor NC group. (C and D) Overexpression of miR-340-5p had no significant effect on BC cell viability, as confirmed by CCK-8 assay results. (E-H) Overexpression of miR-340-5p mimics decreased the speed of the wound closure by $\sim 66 \%$ in MDA-MB-231 cells and by $\sim 72 \%$ in MCF7 cells (both ${ }^{* *} \mathrm{P}<0.01$, compared with the miR-ctrl group). (I-K) Transwell invasion assays showed that overexpression of miR-340-5p mimics could inhibit cell invasion in MDA-MB-231 and MCF7 cells compared with the negative control group. ${ }^{* *} \mathrm{P}<0.01$, compared with the miR-ctrl group. (L) Overexpression or inhibition of miR-340-5p had no influence on the expression of lncPCNAP1 in MCF7 cells. Results are representative of three independent experiments. Data are shown as mean $\pm \mathrm{SD}$. BC, breast cancer; lncRNA, long noncoding RNA; PCNAP1, proliferating cell nuclear antigen pseudogene 1 .

(Fig. 3D and E). To confirm these results, lncRNA PCNAP1 was knocked down in both MBA-MD-231 and MCF7 cells; the knockdown of lncRNA PCNAP1 increased the level of miR-340-5p 2-fold $(\mathrm{P}<0.01)$ as expected (Fig. 3F and G). To validate the binding between these miRNA-340-5p and lncRNA PCNAP1 at an endogenous level, MS2-RNA immunoprecipitation (MS2-RIP) was used to pull down endogenous miRNAs associated with lncRNA PCNAP1. For this purpose, an empty vector (MS2), a vector containing the full sequence of lncRNA PCNAP1, a vector containing IncRNA PCNAP1 with mutations in the miRNA-340-5p targeting binding sites [designated PCNAP1 mut (miRNA-340-5p)], and a vector containing lncRNA PCNAP1 with mutations in the miRNA-340-5p targeting binding sites [PCNAP1-mut (miRNA-340-5p)] were engineered. The RT-qPCR results showed that PCNAP1 RIP was significantly enriched for miRNA-340-5p in MCF7 cells compared with MS2 and the corresponding mutated vector (Fig. 3H). Taken together, these data suggest that miR-340-5p directly binds to lncRNA PCNAP1. By analyzing clinical samples, we found that miR-340-5p expression was decreased in the $\mathrm{BC}$ tissues compared with that noted in the adjacent non-tumor tissues $(\mathrm{P}<0.01)$, and in metastatic $\mathrm{BC}$ tissues compared with non-metastatic tissues $(\mathrm{P}<0.01)$ (Fig. 3I and $\mathrm{J})$, which further verified the results of the above experiments.

IncRNA PCNAPI promotes the migration of BC cells by downregulating miR-340-5p. Next, we investigated whether IncRNA PCNAP1 promotes breast cancer cell migration by interacting with miR-340-5p, according to the bioinformatics predictions. To demonstrate this hypothesis, we transfected miR-340-5p mimics and miR-340-5p inhibitor in MDA-MB-231 and MCF7 cells (Fig. 4A and B). Overexpression of miR-340-5p did not cause significant effects on BC cell viability; this finding was confirmed by consistent results of the CCK- 8 assay (Fig. 4C and D). In wound healing assays, the rate of scratch closure in cells overexpressing miR-340-5p was significantly decreased compared to the negative control: $\mathrm{By} \sim 66 \%(\mathrm{P}<0.01)$ in MDA-MB-231 cells, and by 72\% ( $\mathrm{P}<0.01)$ in MCF7 cells (Fig. 4E-H). Transwell invasion assays showed that the degree of invasion in the overexpressed group was significantly decreased compared with the control group (Fig. 4I-K); this was highly consistent with the lncRNA PCNAP1-knockdown 
A

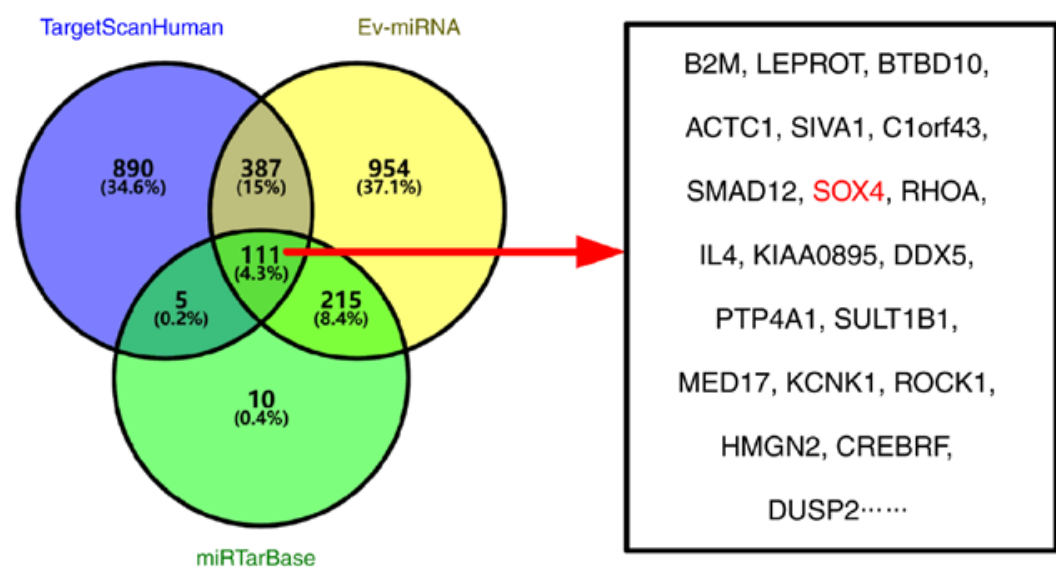

B

\begin{tabular}{|c|c|}
\hline \multicolumn{2}{|c|}{ Predicted consequential pairing of target region (top) and miRNA (bottom) } \\
\hline Position 1801-1807 of SOX4 3'UTR & $5^{\prime} \ldots$ UUUGGAUUUCCUGAUUUUAUAAC...3' \\
\hline & \\
\hline hsa-miR-340-5p & $3^{\prime}$ UUAGUCAGAGUAACGAAAUAUU \\
\hline SOX4-MUT & $5^{\prime} \ldots$ UUUGGAUUUCCUGAUAAAUAUUC...3' \\
\hline Position 2107-2113 of SOX4 3'UTR & $5^{\prime} \ldots$ CUUUUUUGACUUUUUUUAUAAG....3' \\
\hline & \\
\hline hsa-miR-340-5p & $3^{\prime}$ UUAGUCAGAGUAACGAAAUAUU \\
\hline SOX4-MUT & $5^{\prime} \ldots$ CUUUUUUGACUUUUAAAUAUUG...3' \\
\hline
\end{tabular}

C

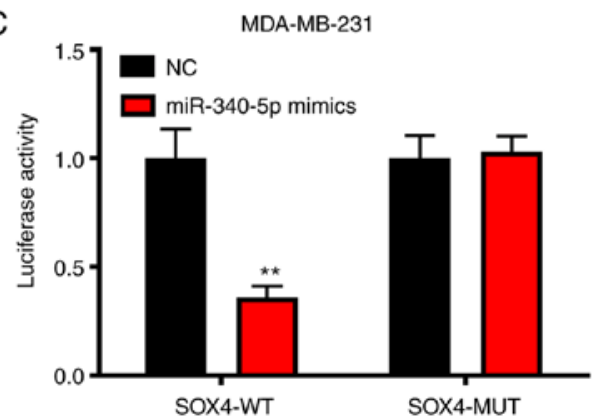

D

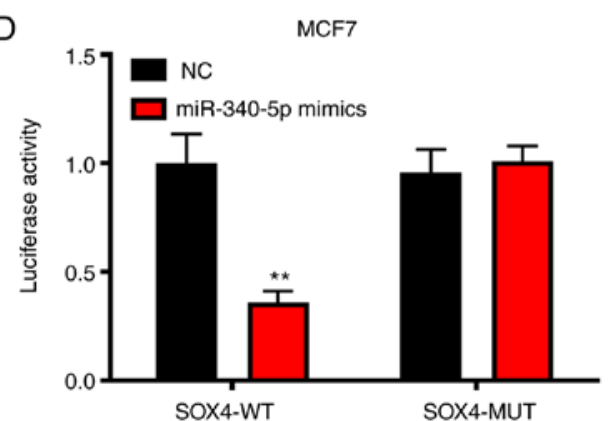

Figure 5. SOX4 has a target relationship with miR-340-5p. (A) TargetScan Human, EV-miRNA, and miRTarBase jointly predicted 111 proteins directly targeted by miR-340-5p, including SOX4. (B) Predicted binding sites between miR-340-5p and SOX4 according to miRcode. (C and D) Luciferase reporter gene assay confirmed the target relationship between miR-340-5p and SOX4 in MDA-MB-231 and MCF7 cells. Results are representative of three independent experiments. Data are shown as mean $\pm \mathrm{SD}$. ${ }^{* *} \mathrm{P}<0.01$, compared with the $\mathrm{NC}$ group. SOX4, SRY-box transcription factor 4.

results. We also found that miR-340-5p mimics and inhibitor did not affect the expression of lncRNA PCNAP1 (Fig. 4L). These results indicate that lncRNA PCNAP1 may promote the migration of BC cells by downregulating miR-340-5p.

SOX4 has a target relationship with $\mathrm{miR}-340-5 \mathrm{p}$. Using TargetScan, we previously predicted that four miRNAs binding to PCNAP1 may target SOX4 directly. In order to verify whether the binding of IncRNA to miR-340-5p could regulate SOX4, we performed in-depth bioinformatics predictions. TargetScan Human, EV-miRNA, and miRTarBase jointly predicted 111 proteins that miR-340-5p directly targeted, including SOX4, suggesting that it was likely to be a miR-340-5p-targeted protein (Fig. 5A). According to miRcode predictions, miR-340-5p can bind to the 3' UTR of SOX4 (Fig. 5B). To verify this result, we performed luciferase reporter assays in both MDA-MB-231 and MCF7 cells, and the reported luciferase contained SOX4-WT as well as SOX4-MUT without potential binding sites. The vector was co-transfected into MDA-MB-231 and MCF7 cells with miR-340-5p mimics and miR-340-5p inhibitor. The miR-340-5p mimics inhibited the luciferase activity of SOX4-WT by $\sim 60$ and $\sim 64 \%$ in MDA-MB-231 and MCF7 cells, respectively, but did not inhibit the luciferase activity of SOX4-MUT $(\mathrm{P}<0.01$ in MDA-MB-231; $\mathrm{P}<0.01$ in MCF7) (Fig. 5C and D), indicating that miRNA-340-5p can directly target SOX4.

IncRNA PCNAPl promotes BC metastasis by downregulating miR-340-5p, then upregulating SOX4. To test whether lncRNA PCNAP1 promotes the metastasis of BC cells by regulating $\mathrm{SOX} 4$, we first analyzed the clinical organization of BC. Immunohistochemistry results showed that SOX4 expression was upregulated in $\mathrm{BC}$ tissues relative to adjacent tissues (Fig. 6A), and RT-qPCR results confirmed this finding (Fig. 6B). Furthermore, the expression of SOX4 was significantly upregulated in tissues of metastatic patients compared 

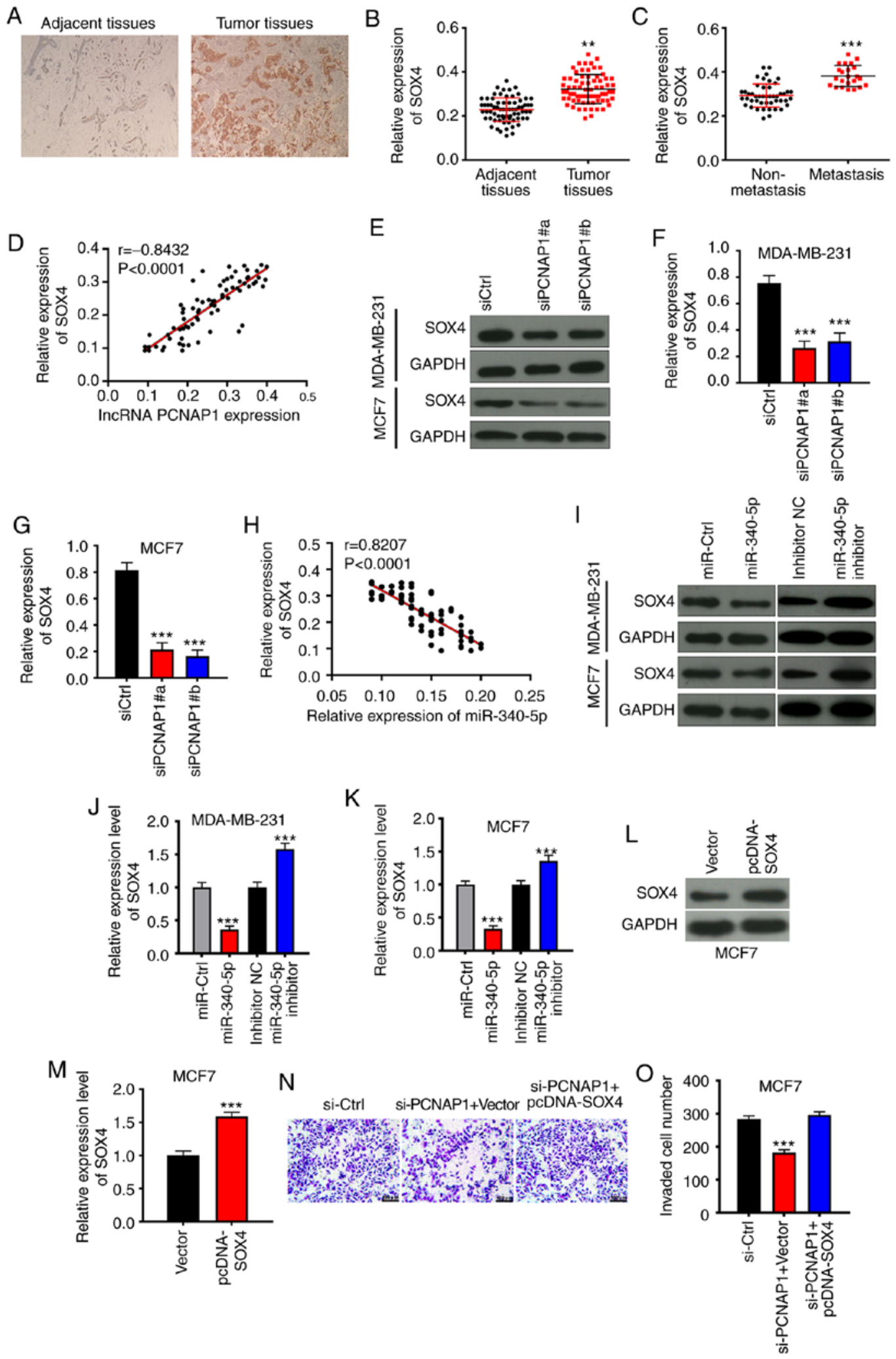

Figure 6. IncRNA PCNAP1 promotes BC metastasis by downregulating miR-340-5p, then upregulating SOX4. (A) Immunohistochemistry results showed that SOX4 was significantly increased in BC tissues compared with that in adjacent normal tissues (magnification, x100). (B) RT-qPCR validation of the immunohistochemistry results. ${ }^{* * *} \mathrm{P}<0.01$, compared with adjacent tissues. (C) SOX4 expression was increased in metastatic BC tissues compared with non-metastatic tissues. ${ }^{* * *} \mathrm{P}<0.001$, compared with non-metastatic tissues. (D) There was a positive correlation between the expression levels of IncRNA PCNAP1 and SOX4 in metastatic tissues. (E-G) Knockdown of PCNAP1 (siPCNAP1\#a and siPCNAP1\#b) significantly suppressed the protein expression of SOX4 in MDA-MB-231 and MCF7 cells compared with the negative control group (siCtrl). ${ }^{* * *} \mathrm{P}<0.001$, compared with the siCtrl group. (H) There was a negative correlation between miR-340-5p and SOX4 expression in metastatic tissues. (I-K) miR-340-5p mimics decreased the protein expression of SOX4 compared with the miR-Ctrl group in MDA-MB-231 and MCF7 cells. ${ }^{* * *} \mathrm{P}<0.001$, compared with the miR-Ctrl group. In contrast, the miR-340-5p inhibitor increased the expression compared with the inhibitor NC group. ${ }^{* * *} \mathrm{P}<0.001$, compared with the inhibitor NC group. ( $\mathrm{L}$ and $\mathrm{M}$ ) Expression of SOX4 was upregulated by the overexpression plasmid. ${ }^{* * * *} \mathrm{P}<0.001$, compared with the vector group. (N and $\mathrm{O}$ ) Knockdown of lncRNA PCNAP1 decreased invasion which was restored by overexpression of SOX4. ${ }^{* * * *} \mathrm{P}<0.001$, compared with the siCtrl group. Results are representative of three independent experiments. Data are shown as mean $\pm \mathrm{SD}$. BC, breast cancer; lncRNA, long noncoding RNA; PCNAP1, proliferating cell nuclear antigen pseudogene 1; SOX4, SRY-box transcription factor 4. 
with those of non-metastatic patients (Fig. 6C). This result was consistent with those obtained for lncRNA PCNAP1 in $\mathrm{BC}$ tissues. Therefore, we performed a correlation analysis for lncRNA PCNAP1 and SOX4 expression in tumor tissues of metastatic patients. The results showed a significant positive correlation between lncRNA PCNAP1 and SOX4 expression in metastatic tissues (Fig. 6D). The expression of SOX4 was also significantly downregulated after knockdown of lncRNA PCNAP in the MDA-MB-231 and MCF7 cells, which confirmed the correlation between the two (Fig. 6E-G). By contrast, miR-340-5p expression was negatively correlated with SOX4 expression in metastatic tissues (Fig. 6H). Western blot analysis confirmed that overexpression of miR-340-5p mimics in MDA-MB-231 and MCF7 cells resulted in a significant downregulation of SOX4 expression; by contrast, the miRNA inhibitor upregulated the expression of SOX4 (Fig. 6I-K). The Transwell assay results also confirmed that invasion of MCF7 was significantly decreased by the knockdown of lncRNA PCNAP1 and restored by the overexpression of SOX4 (Fig. 6L-O). Thus, the above results indicate that the IncRNA promotes the metastasis of breast cancer by downregulating miR-340-5p and consequently upregulating SOX4.

\section{Discussion}

It is well established that mammalian genomes encode large numbers of long non-coding RNAs (lncRNAs) in addition to protein-coding RNAs, and that the majority of these IncRNAs have important functions, they are involved in chromatin remodeling, as well as transcriptional and post-transcriptional regulation, through a variety of chromatin-based mechanisms and via cross-talk with other RNA species (24). With ongoing research, newly identified lncRNAs have emerged as critical factors in cellular development and human diseases including breast cancer. For example, the ectopic expression of IncRNA Smad7 can rescue apoptosis induced by a TGF- $\beta$ receptor inhibitor in breast cancer (25). Gupta et al found that the expression of lncRNA HOTAIR was often high and could be a powerful predictor of metastasis and survival in primary breast cancer (9). Pseudogenes such as proliferating cell nuclear antigen pseudogene 1 (PCNAP1) serve as functional regulators of ancestral gene expression and have important roles in regulating protein-coding transcripts (26), regulating genes via the piRNA pathway for limiting transposable element damage to the genome (27), or acting as a ceRNA (28). PCNAP is exclusively expressed in malignant tissues, including prostate cancer and breast cancer, but not in normal cells, therefore can be used as a cell marker for the classification of different tumors (13). Pseudogene-derived lncRNAs could function as antisense RNAs or endo-siRNAs, or serve as sponges of miRNAs and thus exert biological roles in cancer $(29,30)$. A recent study found that lncRNA PCNAP1 expression levels were significantly increased in liver cancer tissues positive for hepatitis B virus covalently closed circular DNA, suggesting an oncogenic role in this cancer (29). However, the precise molecular mechanisms by which lncRNA PCNAP1 modulates breast cancer (BC) growth remain largely unknown.

Plants, animals, and some viruses also contain miRNAs, which are small noncoding RNA molecules of about 22

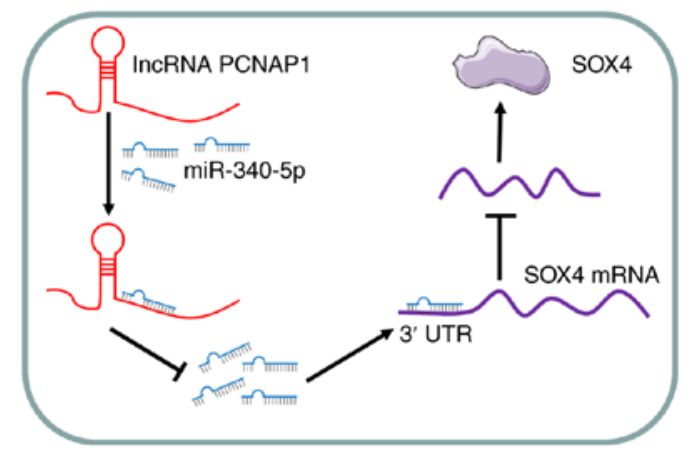

Figure 7. Mechanistic model of lncRNA PCNAP1 promoting breast cancer metastasis via miR-340-5p-dependent upregulation of SOX4. lncRNA, long noncoding RNA; PCNAP1, proliferating cell nuclear antigen pseudogene 1; SOX4, SRY-box transcription factor 4; UTR, untranslated region.

nucleotides. The main role of miRNAs is RNA silencing and negative transcriptional regulation of gene expression $(31,32)$. miRNAs are also key regulators of lncRNAs via complicated and diverse mechanisms. Notably, lncRNAs have recently been found to act as miRNA sponges or miRNA inhibitors (antagomirs), which interact with miRNAs and modulate the expression of miRNA target genes $(33,34)$. Moreover, a lncRNA may act as a competing endogenous RNA (ceRNA), effectively inhibiting the expression of miRNAs (35). Liu et al found that IncRNA HOTAIR could modulate the de-repression of HER2, a target gene of miR-331-3p in gastric cancer (36). There may be some mechanisms by which lncRNAs can degrade miRNAs by binding to miRNAs, similar to the function of miRNA sponges or antagomirs that promote miRNA degradation (37). However, the exact mechanism remains unclear.

In the present study, we found that the average level of lncRNA PCNAP1 in BC was significantly higher than that observed in corresponding non-tumor tissues. Interestingly, patients with metastasis had increased lncRNA PCNAP1 levels compared with patients without metastasis. In addition, we investigated the correlation between lncRNA PCNAP1 levels and prognosis in patients with $\mathrm{BC}$. We found that high expression of lncRNA PCNAP1 in BC tissues was associated with poor prognosis. These findings suggest that lncRNA PCNAP1 plays a critical role in the development and metastasis of BC. An RNA interference approach was used to further analyze the role of lncRNA PCNAP1 in BC cells. Although inhibition of lncRNA PCNAP1 did not affect the growth of BC MDA-MB-231 or MCF7 cells in vitro, its knockdown significantly inhibited the migration and invasion of BC cells, which was further confirmed in mouse transplant models. These results suggest that increased lncRNA PCNAP1 levels in samples with metastasis may be the cause of BC metastasis, rather than a consequence. Mechanistically, we showed that lncRNA PCNAP1 participates, at least partly, in these processes by regulating the expression of SRY-box transcription factor 4 (SOX4) via competitively binding miRNA-340-5p as a ceRNA. Collectively, the present data demonstrated a key causal role of lncRNA PCNAP1 in metastasis of BC, and suggest that it is a potential therapeutic target for BC metastasis.

SOX4, a member of the Sry-related high mobility group box family of transcription factors, is considered a master regulator of tumorigenesis and cancer stemness $(38,39)$. Numerous 
studies have found increased SOX4 expression in various cancers (including lung, colorectal, prostate, and esophageal cancers) (40-43). In the present study, we demonstrated that the knockdown of lncRNA PCNAP1 reduced mRNA and protein levels of SOX4, suggesting that SOX4 may be a downstream target gene regulated by lncRNA PCNAP1. More importantly, overexpression of SOX4 rescued, at least in part, the impaired migration and invasion caused by lncRNA PCNAP1 silencing. This finding indicates that SOX4 participates in the process of metastasis affected by lncRNA PCNAP1 in BC. These comprehensive data are consistent with the results of previous studies. The main molecular functions of lncRNAs are as: i) Decoys to locate transcription factors; ii) regulatory signals for transcription; iii) scaffolds to aggregate different proteins; iv) 'sponges' to interact with miRNAs; and v) guides for binding of specific proteins to target genes (44). In the present study, it was demonstrated that lncRNA PCNAP1 may act as a 'sponge' to interact with miRNA-340-5p, leading to a reduction in miRNA-340-5p levels in BC cells. This decrease in miRNA-340-5p levels abolishes the inhibitory effect of IncRNA PCNAP1 on SOX4, which eventually causes BC metastasis. This suggests that the lncRNA PCNAP1/miRNA-340-5p/SOX4 axis is important in $\mathrm{BC}$ metastasis. Whether other miRNAs function as the 'bridge' linking lncRNA PCNAP1 and SOX4 remains an open question, as 10 miRNAs bound by lncRNA PCNAP1 were predicted to target SOX4 in a similar way. Furthermore, there have been few reports on the role of miRNA-340-5p in cancer development. Although the knockdown of miRNA-340-5p increased the migration and invasion of $\mathrm{BC}$ cells, the detailed mechanism by which this occurs requires further investigation in the future, as does the question of whether miRNA-340-5p influences the development of other cancers.

In summary, the results of the present study demonstrated that high lncRNA PCNAP1 expression levels promote malignant metastasis in BC cells in vitro and in vivo (Fig. 7); thus, lncRNA PCNAP1 has potential as a biomarker for the progression of BC. Moreover, our results suggest that lncRNA PCNAP1 functions as a metastasis-promoting gene in certain types of cancer, paving the way for the development of new therapeutic modalities. Depletion of lncRNA PCNAP1 and even use of an antagonist may be a promising strategy for $\mathrm{BC}$ treatment.

\section{Acknowledgements}

Not applicable.

\section{Funding}

The present study was supported by the Henan Science and Technology Project (grant no. 171022310005).

\section{Availability of data and materials}

All data generated or analyzed during this study are included in this published article.

\section{Authors' contributions}

Conception and design of the research study was accomplished by YY and HL. Administrative support was provided by YH.
Collection and assembly of the data were carried out by $\mathrm{YH}$ and YS. Data analysis and interpretation were conducted by YS and QC. Manuscript writing was carried out by YY and HL. All authors read and approved the manuscript and agree to be accountable for all aspects of the research in ensuring that the accuracy or integrity of any part of the work are appropriately investigated and resolved.

\section{Ethics approval and consent to participate}

The clinical data collection and research procedures were reviewed and approved by the Medical Ethics Committee of Henan Provincial People's Hospital. In addition, BC donors participating in the study provided written informed consent for their tissue samples to be used for scientific research. All animal experiments were performed at the Animal Laboratory Center of Henan Provincial People's Hospital. All experimental procedures and protocols were approved by the Institutional Animal Care and Use Committee at Henan Provincial People's Hospital, in accordance with the Guide for the Care and Use of Laboratory Animals.

\section{Patient consent for publication}

Not applicable.

\section{Competing interests}

The authors declare that they have no competing interests.

\section{References}

1. Playdon MC, Bracken MB, Sanft TB, Ligibel JA, Maura H and Irwin ML: Weight gain after breast cancer diagnosis and all-cause mortality: Systematic review and meta-analysis. J Natl Cancer Inst 107: djv275, 2015.

2. DeSantis CE, Ma J, Gaudet MM, Newman LA, Miller KD, Goding Sauer A, Jemal A and Siegel RL: Breast cancer statistics, 2019. CA Cancer J Clin 69: 438-451, 2019.

3. Chen P, Wang R, Yue Q and Hao M: Long non-coding RNA TTN-AS1 promotes cell growth and metastasis in cervical cancer via miR-573/E2F3. Biochem Biophys Res Commun 503: 2956-2962, 2018.

4. Amaral PP, Dinger ME, Mercer TR and Mattick JS: The eukaryotic genome as an RNA machine. Science 319: 1787-1789, 2008.

5. Guttman M, Amit I, Garber M, French C, Lin MF, Feldser D, Huarte M, Zuk O, Carey BW, Cassady JP, et al: Chromatin signature reveals over a thousand highly conserved large non-coding RNAs in mammals. Nature 458: 223-227, 2009.

6. Amaral PP and Mattick JS: Noncoding RNA in development. Mamm Genome 19: 454-492, 2008.

7. Batista PJ and Chang HY: Long noncoding RNAs: Cellular address codes in development and disease. Cell 152: 1298-1307, 2013.

8. Ginger MR, Shore AN, Contreras A, Rijnkels M, Miller J, Gonzalez-Rimbau MF and Rosen JM: A noncoding RNA is a potential marker of cell fate during mammary gland development. Proc Natl Acad Sci USA 103: 5781-5786, 2006.

9. Gupta RA, Shah N, Wang KC, Kim J, Horlings HM, Wong DJ, Tsai MC, Hung T, Argani P, Rinn JL, et al: Long non-coding RNA HOTAIR reprograms chromatin state to promote cancer metastasis. Nature 464: 1071-1076, 2010.

10. Yuan SX, Yang F, Yang Y, Tao QF, Zhang J, Huang G, Yang Y, Wang RY, Yang S, Huo XS, et al: Long noncoding RNA associated with microvascular invasion in hepatocellular carcinoma promotes angiogenesis and serves as a predictor for hepatocellular carcinoma patients' poor recurrence-free survival after hepatectomy. Hepatology 56: 2231-2241, 2012. 
11. Zhang EB, Kong R, Yin DD, You LH, Sun M, Han L, Xu TP, Xia R, Yang JS, De W and Chen Jf: Long noncoding RNA ANRIL indicates a poor prognosis of gastric cancer and promotes tumor growth by epigenetically silencing of miR-99a/miR-449a. Oncotarget 5: 2276-2292, 2014.

12. Yang F, Shen Y, Zhang W, Jin J, Huang D, Fang H, Ji W, Shi Y, Tang L, Chen W, et al: An androgen receptor negatively induced long non-coding RNA ARNILA binding to miR-204 promotes the invasion and metastasis of triple-negative breast cancer. Cell Death Differ 25: 2209-2220, 2018.

13. Feng J, Yang G, Liu Y, Gao Y, Zhao M, Bu Y, Yuan H, Yuan Y, Yun $\mathrm{H}$, Sun M, et al: IncRNA PCNAP1 modulates hepatitis B virus replication and enhances tumor growth of liver cancer. Theranostics 9: 5227-5245, 2019.

14. Park SY, Jeong MS, Han CW, Yu HS and Jang SB: Structural and functional insight into proliferating cell nuclear antigen. J Microbiol Biotechnol 26: 637-647, 2016.

15. Albus U: Guide for the care and use of laboratory animals (8th edn). Lab Anim 46: 267-268, 2012.

16. Salmon HW, Guha A, Rojiani AM and Siemann DW: Vascular development in mouse lung metastases. Am J Cancer Res 2 : 581-588, 2012.

17. Lewis BP, Burge CB and Bartel DP: Conserved seed pairing, often flanked by adenosines, indicates that thousands of human genes are microRNA targets. Cell 120: 15-20, 2005.

18. Liu T, Zhang Q, Zhang J, Li C, Miao YR, Lei Q, Li Q and Guo AY: EVmiRNA: A database of miRNA profiling in extracellular vesicles. Nucleic Acids Res 47 (D1): D89-D93, 2019.

19. Hsu SD, Lin FM, Wu WY, Liang C, Huang WC, Chan WL, Tsai WT, Chen GZ, Lee CJ, Chiu CM, et al: miRTarBase: A database curates experimentally validated microRNA-target interactions. Nucleic Acids Res 39 (Database Issue): D163-D169, 2011.

20. Jeggari A, Marks DS and Larsson E: miRcode: A map of putative microRNA target sites in the long non-coding transcriptome. Bioinformatics 28: 2062-2063, 2012.

21. Livak KJ and Schmittgen TD: Analysis of relative gene expression data using real-time quantitative PCR and the 2(-Delta Delta C(T)) method. Methods 25: 402-408, 2001.

22. Yuan JH, Yang F, Wang F, Ma JZ, Guo YJ, Tao QF, Liu F, Pan W, Wang TT, Zhou CC, et al: A long noncoding RNA activated by TGF- $\beta$ promotes the invasion-metastasis cascade in hepatocellular carcinoma. Cancer Cell 25: 666-681, 2014.

23. Zhang J, Liang Q, Lei Y, Yao M, Li L, Gao X, Feng J, Zhang Y, Gao H, Liu DX, et al: SOX4 induces epithelial-mesenchymal transition and contributes to breast cancer progression. Cancer Res 72: 4597-4608, 2012.

24. Fang $\mathrm{Y}$ and Fullwood MJ: Roles, functions, and mechanisms of long non-coding RNAs in cancer. Genomics Proteomics Bioinformatics 14: 42-54, 2016.

25. Arase M, Horiguchi K, Ehata S, Morikawa M, Tsutsumi S, Aburatani H, Miyazono K and Koinuma D: Transforming growth factor- $\beta$-induced lncRNA-Smad7 inhibits apoptosis of mouse breast cancer JygMC(A) cells. Cancer Sci 105: 974-982, 2014.

26. Chan WL and Chang JG: Pseudogene-derived endogenous siRNAs and their function. Methods Mol Biol 1167: 227-239, 2014.

27. Siomi MC, Sato K, Pezic D and Aravin AA: PIWI-interacting small RNAs: The vanguard of genome defence. Nat Rev Mol Cell Biol 12: 246-258, 2011.
28. Karreth FA, Reschke M, Ruocco A, Ng C, Chapuy B, Léopold V, Sjoberg M, Keane TM, Verma A, Ala U, et al: The BRAF pseudogene functions as a competitive endogenous RNA and induces lymphoma in vivo. Cell 161: 319-332, 2015.

29. Dinger ME, Amaral PP, Mercer TR, Pang KC, Bruce SJ, Gardiner BB, Askarian-Amiri ME, Ru K, Soldà G, Simons C, et al: Long noncoding RNAs in mouse embryonic stem cell pluripotency and differentiation. Genome Res 18: 1433-1445, 2008.

30. Lou W, Ding B and Fu P: Pseudogene-derived lncRNAs and their miRNA sponging mechanism in human cancer. Front Cell Dev Biol 8: 85, 2020.

31. Bartel DP: MicroRNAs: Genomics, biogenesis, mechanism, and function. Cell 116: 281-297, 2004.

32. Ambros V: The functions of animal microRNAs. Nature 431: 350-355, 2004

33. Kallen AN, Zhou XB, Xu J, Qiao C, Ma J, Yan L, Lu L, Liu C, Yi JS, Zhang H, et al: The imprinted H19 lncRNA antagonizes let-7 microRNAs. Mol Cell 52: 101-112, 2013.

34. Wang K, Long B, Zhou LY, Liu F, Zhou QY, Liu CY, Fan YY and Li PF: CARL lncRNA inhibits anoxia-induced mitochondrial fission and apoptosis in cardiomyocytes by impairing miR-539-dependent PHB2 downregulation. Nat Commun 5: 3596, 2014.

35. Tay Y, Rinn J and Pandolfi PP: The multilayered complexity of ceRNA crosstalk and competition. Nature 505: 344-352, 2014.

36. Liu XH, Sun M, Nie FQ, Ge YB, Zhang EB, Yin DD, Kong R, $\mathrm{Xia} \mathrm{R}, \mathrm{Lu} \mathrm{KH}$, Li JH, et al: lnc RNA HOTAIR functions as a competing endogenous RNA to regulate HER2 expression by sponging miR-331-3p in gastric cancer. Mol Cancer 13: 92, 2014.

37. Wang K, Liu F, Zhou LY, Long B, Yuan SM, Wang Y, Liu CY, Sun T, Zhang XJ and Li PF: The long noncoding RNA CHRF regulates cardiac hypertrophy by targeting miR-489. Circ Res 114: 1377-1388, 2014.

38. Parvani JG and Schiemann WP: Sox4, EMT programs, and the metastatic progression of breast cancers: Mastering the masters of EMT. Breast Cancer Res 15: R72, 2013.

39. Vervoort SJ, van Boxtel R and Coffer PJ: The role of SRY-related HMG box transcription factor 4 (SOX4) in tumorigenesis and metastasis: Friend or foe? Oncogene 32: 3397-3409, 2013.

40. Bilir B, Osunkoya AO, Wiles WG IV, Sannigrahi S, Lefebvre V, Metzger D, Spyropoulos DD, Martin WD and Moreno CS: SOX4 is essential for prostate tumorigenesis initiated by PTEN ablation. Cancer Res 76: 1112-1121, 2016.

41. Koumangoye RB, Andl T, Taubenslag KJ, Zilberman ST, Taylor CJ, Loomans HA and Andl CD: SOX4 interacts with EZH2 and HDAC3 to suppress microRNA-31 in invasive esophageal cancer cells. Mol Cancer 14: 24, 2015.

42. Wang B, Li Y, Tan F and Xiao Z: Increased expression of SOX4 is associated with colorectal cancer progression. Tumour Biol 37: 9131-9137, 2016.

43. Zhou Y, Wang X, Huang Y, Chen Y, Zhao G, Yao Q, Jin C, Huang Y, Liu X and Li G: Down-regulated SOX4 expression suppresses cell proliferation, metastasis and induces apoptosis in Xuanwei female lung cancer patients. J Cell Biochem 116: 1007-1018, 2015

44. Wang KC and Chang HY: Molecular mechanisms of long noncoding RNAs. Mol Cell 43: 904-914, 2011.

(i) $($ This work is licensed under a Creative Commons Attribution-NonCommercial-NoDerivatives 4.0 International (CC BY-NC-ND 4.0) License. 